\title{
A interpretação da diferença dos sexos: inferioridade, estranheza, variedade, igualdade
}

The interpretation of the difference between the sexes: inferiority, strangeness, variety, equality

La interpretación de la diferencia entre los sexos: inferioridad, extranñeza, variedad, igualdad

Jacqueline Barus-Michel

\begin{abstract}
Resumo
Até hoje, a constância da subordinação das mulheres, através das épocas e das sociedades, faz da diferença dos sexos um problema específico da relação com o outro. $\mathrm{O}$ estatuto social da mulher é efeito de um processo complexo que combina as constituições orgânicas (natureza) e sua transposição metafórica para construções culturais, com ambivalências e denegações dos desejos e das angústias mais profundas, ou seja, com as exigências de ordem social e de reprodução deste. São as transformações do espírito crítico e da emancipação cultural que livram do domínio efetivo original da natureza e restituem a diferença dos sexos às dimensões de uma variação da espécie. Esse processo só pode ser compreendido quando se recorre, entre outras disciplinas, à antropologia, à fisiologia, à sociologia, à psicanálise e à história.
\end{abstract}

Palavras-chave: Diferença dos sexos. Estatuto da mulher. Cultura. Realidade psíquica. Gênero.

\section{Abstract}

Until today, the constancy of the subordination of women, through the ages and societies, makes the difference between the sexes a more specific problem when referring it to the relationship, one with another. The social status of women is the effect of a complex process that combines the organic constitutions (nature) and its metaphorical transposition to cultural constructions, with ambivalence and degradation of desires anxieties deepen, in other words, with the demands of social order and reproduction of this demands. Are the transformations of critical spirit and cultural emancipation that which will bring about a domino effect restoring the natural balance of the sexes to the dimensions of

Professora emérita da Universidade de Paris 7 (Paris-Diderot), membro do Laboratoire de Changement Social dessa mesma universidade. 
a variation of the species. This process can only be understood when one uses, among other disciplines, anthropology, physiology, sociology, psychoanalysis and history.

Keywords: Difference sex, status of women, Culture, Psychic Reality, Genre.

\section{Resumen}

Hasta ahora, la constancia de la subordinación de las mujeres a través de los siglos y de las sociedades, hace de la diferencia entre los sexos un problema específico de relación con el otro. El estatuto social de la mujer es el efecto de un proceso complejo que combina las constituciones orgánicas (la naturaleza) y su transposición metafórica a las construcciones culturales, con ambivalencias y renuncias de los deseos y angustias más profundos, es decir, con las exigencias de orden social y reproducción. Las transformaciones del espíritu crítico y de la emancipación cultural son las que libertan del dominio efectivo original de la naturaleza y restituyen la diferencia entre los sexos a las dimensiones de una variación de la especie. Este proceso sólo se puede entender cuando se relaciona, entre otras disciplinas, con la antropología, con la fisiología, con la sociología, con el psicoanálisis y con la historia.

Palabras clave: Diferencia entre los sexos, Estatuto de la mujer, Cultura, Realidad psíquica, Género.

\section{Résumé}

Jusque ici, la constance, à travers époques et sociétés, de la subordination des femmes fait de la différence des sexes un problème spécifique de la relation à l'autre. Le statut social de la femme est l'effet d'un processus complexe qui combine les constitutions organiques (nature), leur transposition métaphorique dans des constructions culturelles, avec les ambivalences et les dénis des désirs et des angoisses les plus profonds, enfin avec les exigences d'ordre social et de reproduction du même. Ce sont les transformations de l'esprit critique et de l'émancipation culturelle qui arrivent à dégager de l'emprise effective originelle de la nature et à restituer la différence des sexes aux dimensions d'une variation de l'espèce. Processus qui ne 'peut être compris qu'en faisant appel, entre autres, à l'anthropologie, à la physiologie, à la sociologie, à la psychanalyse et à l'histoire...

Mots clés: Différence des sexes. Statut de la femme. Culture. Réalité psychique. Genre. 


\section{$1 \mathrm{O}$ outro, a diferença}

0 outro, o diferente, ao mesmo tempo espelho e ameaça, sempre aparece como objeto de interrogação. A diferença exige sempre ser trabalhada. O corpo do outro é desejado para o prazer e para a cooperação, para a troca e para o reconhecimento. Ele é desejado e necessário (vida), ele é amado, temido, odiado (morte), ele pode ser a presa ou o assassino. Esse dilema, hegeliano e freudiano, concretiza-se na ideia do semelhante, na igualdade (irmão, cidadão, aliado), que remete à política e à ética, bem como, inversamente, ao sentimento e na ideia de estranho, inimigo, rival (e até nisso semelhante). Ele suscita, então, reações e ações defensivas, agressivas ou mesmo mortíferas.

A diferença de sexo é um caso à parte. Não é certo que a mulher seja reconhecida como um outro, um semelhante ou um igual, tanto atual quanto potencial. Em todos os tempos, em todas as sociedades, ela foi colocada num lugar de inferioridade, destinada à reprodução e às tarefas domésticas. As mulheres que tiveram acesso a outras funçôes, que puderam tomar a palavra, assumindo algum poder nas esferas que escapam ao espaço doméstico, foram vistas como exceções não significativas. A diferença sexual, a única que existe na natureza da espécie, não fortuita, sempre foi tomada como um indício, para as mulheres, de uma inferioridade nata, justificando as proibições sociais e as formas de tratamento que as relegavam a um plano inferior. Ora, se num primeiro momento, o outro, o diferente, pode ser considerado um semelhante, no outro, a diferença inscrita na natureza passaria a indicar, justamente, não uma diferença, mas uma outra natureza.

Para compreendermos os efeitos da diferença de sexo na espécie humana, que é complexa e paradoxal, necessitamos de uma abordagem transdisciplinar. É claro que se pode vislumbrar aqui a oposição natureza/ cultura, assim como a interdependência do psicológico e do social, da subjetividade e do estatuto social, podendo-se ainda intercalar temas como identidade (ser mulher), poder (submissão/dominação), gozo e sofrimento (desejo/falta). Tais problemas são também colocados em termos de história, de evolução, bem como em termos biológicos.

A diferença da mulher, no entanto, gera representações contraditórias: perigo, demônio, podridão, pureza, beleza, fertilidade, além das ambivalências sedução/proteção, fidelidade/traição, poder/fragilidade, frivolidade/malignidade. O trio de imagens perturbadoras (virgem, mãe, prostituta) é considerado uma espécie de parâmetro para definir os 
estatutos aos quais se podem ajuntar outros, como feiticeira, possuída pelo demônio ou histérica. A mulher é objeto de todas as representaçôes, tanto do malfeito quanto do benfeito, do cuidado, quando ela se dedica ao serviço do outro (a criança), embora fique aí numa situação de submissão, de dependência, de compaixão frente ao sofrimento do outro.

Para os pensadores e homens de ciência, a mulher é um enigma e, nesse caso, um insucesso para o conhecimento, "mistério feminino, continente negro". Mistério do corpo que gera, mistério de suas profundezas, de suas perdas de sangue, de seus órgãos sexuais e seus prazeres ambíguos (clitóris, ponto $G)$.

O século XXI ainda tem dificuldades diante desse enigma. Daí as perguntas: quem é ela, o que ela pode, o que ela quer, o que ela merece? Essas perguntas são resolvidas universalmente pela submissão, à maneira da domesticação, como um animal selvagem. A mulher, por esse mistério não resolvido, é assimilável à natureza selvagem, ou seja, ela não é um outro, é um animal.

A noção de uma humanidade partilhada que encontramos em algumas religiões, nos séculos passados, não chega à representação da mulher como um semelhante e menos ainda como um ser de igualdade, em relação ao homem. Isso remete a um recalque, à denegação que atinge a lógica e a razão, mas que tira daí sua força e mergulha em afetos como medo, desejo, inveja.

\section{Um pouco de história}

A natureza humana da mulher é afirmada na Bíblia, ainda que ela seja diferente, pois gerada secundariamente de uma costela, com o destino de ser uma companheira. Ela é mais valorizada no cristianismo, no papel da Virgem-mãe, embora as mulheres não sejam reconhecidas em igualdade de papéis, mas como servas.

Excepcionalmente, algumas mulheres reivindicadoras, junto com alguns homens, levantaram a hipótese de um mesmo potencial intelectual, moral e afetivo, o que poderia elevá-las à condição de igual. Isso se deu na Idade das Luzes (Madame du Châtelet), na Revolução Francesa (Olympe de Gouges), no século XIX, no Ocidente. Nesses casos, elas foram consideradas como exceção, daí a suspeita de que queriam ser homens. Ou seja, se a mulher que encarna a igualdade quer ser um homem, quer tomar seu lugar, ela não é, por isso mesmo, um semelhante. 
Foi na virada do século XIX para o século XX que as lutas políticas, em especial as reivindicações das sufragistas ${ }^{1}$ tiveram melhor acolhida e que a ideia foi se instalando, pouco a pouco. Mas isso só ocorreu no Ocidente, onde a mulher poderia ter a mesma igualdade que o homem, sendo não uma cópia dele, mas um semelhante, naquilo que constitui a humanidade, ou seja, em seus direitos. Isso, no entanto, está longe de se realizar, em todos os domínios que dependem das leis e dizem respeito aos costumes, à sexualidade, ao trabalho, ao dinheiro, ao poder. O reconhecimento da mulher não se dá nem no plano da consciência e nem da ciência.

A ciência médica, particularmente a neurologia, ainda hesitante, reconhece algumas analogias e descobre as diferenças relativas a nuances, nas atitudes dos homens e das mulheres. A sociologia trabalha com estatísticas e mostra que as meninas parecem progredir mais rápido que os meninos, mas hesita, assim como a psicologia, entre aquilo que é devido à cultura e à natureza. Simone de Beauvoir (1949) já dizia "Não se nasce mulher, torna-se mulher". Lacan (1975) afirma que "a mulher é não toda". Freud (1932) disse que a mulher é incapaz de sublimar, percebe-se castrada e permanece na inveja do pênis, sendo a criança uma compensação dessa inveja.

As feministas reclamam sua diferença como um privilégio, como uma especificidade em todos os domínios, exigindo um acesso a todos os privilégios dos homens, excluindo-os, se for preciso. Hoje, entende-se como gênero o sexo construído, a representação que se faz dele como própria. Mas aí tudo é denegação, tudo é cultura? O que é essa diferença, o que ela quer dizer? O que ela significa para nós, humanos? Voltemos, então, àquilo que é realidade incontornável e às representaçôes que dela fazemos, ao sentido que lhe damos: isso responde a quais motivos (angústia, desejo), visa a quais benefícios?

\section{$3 \mathrm{O}$ suporte da realidade. A realidade do espírito, o pensamento}

O que é mesmo que pesa, na diferença? É um processo estrutural de representação. O pensamento, para construir sentidos, apoia-se em combinações baseadas em diferenças elementares, em oposições. A diferença obriga o espírito humano a uma comparação que é apenas perceptiva, por meio da imagem, da forma, da cor, da sonoridade, da quantidade, etc. Mas isso implica um julgamento fundado em afetos, valorizado, apreciado, de alguma forma, como prazer/desprazer, indo do melhor ao pior, com gradações intermediárias, raramente passando pelo neutro, pela igualdade ou pela

${ }^{1}$ Mulheres que lutavam pelo direito ao voto feminino nas eleiçōes. (N.T.) 
indiferença. A menor diferença conduz a um julgamento que condena uma das partes a uma inferioridade e a outra à superioridade e, daí, à dominação que, caso encontre objeção ou resistência, evolui rapidamente para a violência. Talvez só na matemática encontremos igualdades ante as quais o espírito se inclina em nome do rigor lógico e a razão se distancia do afeto. Ver, conhecer, perceber e tomar consciência são momentos acompanhados de julgamento de valor. Mesmo o julgamento quantitativo se liga aos afetos. Para Freud (1926), o laço representaçãoafeto é genético. Os critérios de julgamento (valores) são fundados na sensibilidade e na cultura: são eróticos (prazer/desprazer), morais (bem/ mal), estéticos (belo/feio), econômicos (rico/pobre) e impactam todos os campos susceptíveis de apreciação, ou seja, eles apresentam variaçôes que têm efeitos na subjetividade.

Nada escapa a isso, exceto as abstrações e símbolos invariáveis (números, símbolos químicos), que são construídos pelo pensamento que quer abolir o afeto, fundar a razão e a ciência. O raciocínio precisa de pontos fixos que ele elabora para seus procedimentos. Tais pontos são objetos do pensamento, em oposição ao julgamento, este também uma produção da consciência. É verdade que é impossível dizermos se há, na natureza, objetos não susceptíveis de variação (a relatividade de Einstein, espaçotempo, é uma construção). Deus seria o eterno ponto de referência que também o pensamento inventou. $\mathrm{O}$ zero da matemática serve de ponto móvel para a escala dos números e valores matemáticos, ele não existe na natureza, mas se presta ao cálculo, nas representações que lhe damos, e só representa uma variação entre dois contrários, mesmo quando se trata de uma hipótese de ausência ou imobilização (por exemplo: temperatura $0^{\circ}$ ).

Ora, uma diferença visível universalmente, que afeta todos os humanos de todas as sociedades e condiciona sua existência, é a diferença dos sexos, uma variação "natural" do humano (e de outras espécies) que só conhece duas formas, mesmo que ela não seja tão rígida como se quer pensá-la. Colocando à parte as aparências tidas como anomalias, como o hermafroditismo, a diferenciação é progressiva, ela pode ser visível e caracterizada nos adultos, com menos clareza nas crianças e nos velhos, para os quais os caracteres físicos ainda não aparecem ou já desaparecem (pilosidade, voz).

A essa diferença natural ajunte-se aquela da cultura, que atualmente denominamos gênero, ou seja, as atribuições sociais, históricas, de identidade e de pertencimento psicológico, comportamental, referente a um ou outro sexo. 
Os dois termos da diferença são pensamentos como oposição e associados a um julgamento de valor: universalmente, o julgamento corrente atribui a superioridade ao homem, ao "ser homem", e a inferioridade ao "ser mulher". Essa desigualdade é pensada como natural, cada homem e cada mulher devendo manifestá-la e confirmá-la em sua vida, em seu comportamento e disposiçôes.

A permanência dessa atribuição de inferioridade à mulher pede explicações, ela se apoia em elementos de realidade, tais como:

- realidade do corpo: a diferença mais clara entre os humanos é a do sexo, ela é concreta, encarnada, irreversível, exceto por malformação, acidente ou intervenção cirúrgica, e divide a humanidade em duas. Essa diferença de sexo não é partilhada nem partilhável, ela torna um estranho ao outro. A partir daí, segundo Héritier (2005), ela estrutura todas as diferenciações. Mas de que é feito esse elemento incomensurável que alimenta as representaçôes e julgamentos?;

- a morfologia: um corpo com uma abertura, que é continente, fértil e produtor, oposto a um corpo impermeável, munido de um órgão erétil e penetrante. A mulher é o objeto (sofre) de fluxos, de perda de sangue, de líquidos, do leite;

- espaço-tempo: essa díade é também contrastada. A mulher se submete a uma ritmicidade: menstruação, gravidez, ambas ausentes no homem; ela é contida em seus deslocamentos, na gravidez, no aleitamento, na dependência dos filhos. Assim, seu espaço sofre limitações, seu tempo é escandido. Seu corpo passa por modificações que tendem ao peso dos seios, do ventre, dos quadris. Em outras palavras, a fisiologia e a morfologia a confinam em uma postura e uma imobilidade que, por sua vez, a designam para a reprodução, para os cuidados com os filhos, as tarefas da casa.

O corpo do homem está predisponível ao deslocamento, ao esforço muscular, à expansão e à predação, à caça. Isso o designa às atividades de conquista, de descoberta, mais livres e agressivas.

Ora, a morfologia e a anatomia visíveis vão servir como apoio metafórico a todas as representações, diferenciadas em oposições radicais, justificando-as e naturalizando-as: a mulher passiva, o homem ativo; a mulher subordinada às crianças e ao homem, o homem dominando a natureza, criando e enriquecendo seu universo. Metaforicamente, a mulher é um recipiente, e o homem uma espada armada para a dominação, para a conquista, a viagem, a aventura, o risco (a morte), enquanto a mulher 
recebe, contém, conserva, protege, permanece na casa, encarnando a estabilidade e o devotamento. A mulher é, assim, destinada à inferioridade que se estende a todos os planos: menos inteligente, menos dotada, naturalmente serva. Reduzida a seu corpo, ela é fêmea e não mulher, ao risco de não ser nem igual, nem semelhante: ela é complemento, instrumento.

\subsection{Realidade psíquica (fantasias)}

O que querem eles, homem e mulher? Os dois querem ser completos, estar no gozo, o corpo pleno, reencontrar a fantasia arcaica, serem conteúdo e continente, os dois experimentando a falta do que o outro tem, portanto, desejantes, mas, ao mesmo tempo, vivendo o medo da alteridade que os completaria, a angústia de afrontar a perda, negada ou atenuada por posturas de submissão ou predação, pelas oscilações de um e outro lado. Os homens estão equipados para a predação e a adotam mais facilmente como realização defensiva, mas suas fantasias são paradoxais, ambivalentes, suas realizações servem para protegê-los do inverso sempre presente (gozo através do outro, faço aquilo que fizeram comigo). A pulsão é sempre dupla, ela invade e transborda o sujeito e o outro.

O desejo de poder, de dominação, está com os dois sexos, mesmo quando ele se exprime pelo seu contrário, passividade ou submissão, favorecido pelas disposições físicas ou pela história psíquica, isto é, pela identificação com as normas ou com as variações das formações neuróticas.

Se o homem e a mulher são comparáveis em suas aspirações mais profundas, suas conformações orientam diferentemente suas posições físicas. Assim, o vazio desejante, provável desejo insatisfeito, e o ventre fecundo, mesmo gerando homens, que são o signo de um poder sobrenatural, suscitam uma angústia contrabalançada defensivamente por um controle severo, submetendo a mulher ao poder e ao benquerer exclusivos do homem. Este pode, então, acreditar que é o senhor de tudo que, justamente, ele teme e inveja. A plenitude passa pelo gozo e pelo poder, tendo-os ou não. Nessa concupiscência, é preciso substituir os filhos pelo falo e pela posse da mulher. A mulher deve então criar os filhos para o homem, e este reina, podendo, assim, acreditar-se dono de tudo. A mulher deve se convencer disso, pois ela não é nem mesmo dona de seu corpo, ela adere a uma metáfora que lhe explica o seu destino. 


\subsection{Da metáfora à fantasia, na psicanálise}

Para Lacan, o Pai é figura da lei, poder significado pelo Falo, ele inaugura a dimensão simbólica. E as mulheres, elas são uma metáfora de quê? De um vazio, da incompletude, no melhor dos casos de um continente. Elas são objeto de fantasias (abrigo quente e penetrável), mas essa fantasia não é simbólica, é um fantasma, é imagem e afeto: em vez de as transcender, este as reenvia à natureza matricial e enigmática, à sua anatomia, obscura metáfora de seu ser. Figura e fantasia funcionam ao inverso uma da outra: de um lado, o Pai, Um, inteiro, guardião do símbolo, o Falo; de outro, a mulher "não toda", continente à espera, a quem falta sempre o órgão do qual ela se acredita desprovida, do qual ela tem inveja (o pênis). O pênis se torna o objeto que alimenta suas fantasias, que a liga aos traços do homem, metáfora viva do Falo (ela, seu corpo é metáfora daquilo que ela é; ele é metáfora do Falo). Para ela, de qualquer modo, não só ele o tem, mas ele o é. Ela passa do desejo de ser completada ao medo de ser destruída... um pouco mais.

Por que o ventre fecundo não tem o mesmo poder? Porque ele é transitório, terreno sazonal para produzir, entre outras coisas, machos dotados de pênis e que, predestinados à independência, nutrir-se-ão dele, em primeiro lugar, e depois farão dele objeto de exploração. Eles guardarão na memória os traços do gozo de um continente que alimenta, mas também do risco de serem por ele aprisionados. As mulheres continuarão sendo um obscuro objeto de desejo e de medo: objeto continente negro, mistério feminino, logo perigosas feiticeiras. Elas próprias parecem viver seus corpos como um destino, pois a natureza e o homem as obrigam a isso.

\section{Uma constatação antropológica}

A diferença é manifesta, natural, estreitamente ligada à reprodução da espécie. Resta dar-lhe um estatuto em todas as outras dimensões e em todos os outros momentos da vida coletiva, na qual os dois sexos poderiam estar lado a lado. Trata-se aqui de interpretar essa diferença e de lhe atribuir um sentido e um estatuto no qual o órgão e a função ficariam a priori mudos: na vida social prática ou intelectual, há lugar para as relaçôes, as trocas.

O tratamento da diferença se faz, então, segundo critérios de cultura, desenvolvidos por meio dos sistemas de representação (imaginário social, tradição, crenças, religião, conhecimentos) que encontram sua legitimidade ao tomar o corpo como metáfora do ser. Precisando estabilizar e hierarquizar as relações e as práticas, esses sistemas tornam-se sacralizados. Tudo que é 
considerado de pouco valor ou negativo corre o risco de discriminação, estigmatização, exploração, maus-tratos, exclusão, aniquilação.

No entanto, uma grande rigidez sufocaria a dinâmica das trocas, embora uma categoria desprezada (no caso a das mulheres) possa ser gratificada com atributos positivos que refletem a incerteza e a ambivalência quanto aos critérios e aos tratamentos a ela impostos, favorecendo aproximações que escapam à desigualdade de princípio.

Os seres inferiorizados se veem dotados, em compensação, de qualidades como charme, doçura, devotamento, bondade, fidelidade, tudo isso podendo rapidamente converter-se em seu contrário: infidelidade, malícia, frivolidades, besteiras, mentira. Essas contradições preparam bem o terreno para certa fluidez nas relaçôes, arranjando as notáveis ambivalências que aí estão subjacentes.

As culturas e sistemas sociais se esforçam quase universalmente para manter severamente, ao longo dos séculos, por meio da ficção e da repressão, uma ordem que negava a uma parte da espécie aquilo que é sua especificidade, isto é, a consciência que reflete (Homo sapiens-sapiens). A parte fêmea, na reprodução, prevaleceu sobre o todo, tanto é que ela marcou a diferença morfológica que lhe estava associada. Por causa da gestação e de seu órgão, o acesso ao pensamento criativo e à partilha do poder foi negado às mulheres, vistas como menos humanas e mais como fêmeas do Homo sapiens. Eis aí a mulher considerada como uma subespécie a serviço da espécie homem.

A confusão dos sexos devida à escolha sexual do mesmo, ao hermafroditismo, a uma opção de transexualidade, ou simplesmente à preferência sexual pelo mesmo, é geralmente objeto de escândalo, aos olhos da sociedade e de suas normas. Com efeito, isso é uma reviravolta num sistema de representaçôes, num sistema simbólico e na ordem social que pretendem sustentar sua legitimidade nos elementos intangíveis da natureza.

A relatividade sexual, erótica e, por isso mesmo, social, não parece ser admissível. A medicina e, em seguida, a psicanálise declararam, durante muito tempo, que essas manifestações intempestivas eram patológicas. A mulher aprisionada na natureza, o homem destinado à aventura humana, ou seja, à cultura: daí o maniqueísmo, cujo simplismo é sempre difícil perceber, dada a complexidade de sua montagem.

Será preciso que o pensamento tome suficientemente a dianteira sobre 
o corpo, pela força da ciência e da técnica, para que a mulher possa se desatar dos entraves naturais e imaginários de seu sexo. Mas isso só está começando a ocorrer nas sociedades ocidentais, quando a dominação das religióes e das tradiçôes se inclina diante do pensamento crítico. Ou em casos excepcionais que revelam a força de caráter de uma mulher, bem como a regressão dos preconceitos em seu meio imediato. A homossexualidade e o transexualismo (terceiro sexo) seguirão o mesmo trajeto.

É a ciência que deu às mulheres os meios de controlar a natalidade, de parir sem dor, chegando à liberdade de escolher suas formas de gozo, que é parte essencial da liberação sexual; a partir daí, ela pode obter os mesmos direitos, adquirir os mesmos conhecimentos e participar das mesmas realizações.

A metaforização do ser por meio de seu corpo, ou do pensamento, por meio das aparências do órgão, escondia as fraquezas e o risco de que, um dia, outra verdade fosse revelada, ou seja, aquela do potencial de desejo e de atitudes sufocada por milênios de dominação desconfiada dos machos. Quanto mais essa parte teve chance de dedicar-se ao saber, mais a fêmea da espécie se emancipou, a ponto de ser considerada como uma semelhante. Mas restam ainda as ambivalências (medo e inveja) que geram aquela mínima diferença do cromossomo escondido na célula, o eterno ponto de interrogação sobre aquilo que ele funda, no seio da espécie.

\section{Uma outra partilha?}

Como é possível a partilha entre semelhantes? As possibilidades se manifestaram no Ocidente, no século XX, em favor do desenvolvimento do pensamento crítico, dos progressos da ciência e, em seguida, das opções políticas. É certo que apareceram casos isolados e mais ou menos escandalosos de mulheres livres ou dominantes. São exceções atribuídas a qualidades peculiares, às circunstâncias, a uma virilidade dissimulada. Conhecemos determinadas tribos chinesas matrilineares (os Khasis, os $\mathrm{Na}$ ), nas quais as mulheres dominam por tradição e nas quais, aliás, os homens estão hoje buscando sua revanche. Certamente foi necessário um longo isolamento (ao sopé do Himalaia) e o peso de uma tradição erigida em sistema, cuja origem é desconhecida.

\section{$5.1 \mathrm{O}$ gênero}

Hoje as mulheres querem ser, pensar, fazer; elas têm distintas maneiras para se acharem semelhantes. No entanto, é difícil conceber que o outro possa 
ser diferente sem ser o inverso, melhor ou nem tanto. Há o peso das estruturas do pensamento, das culturas, da história, a aparente evidência das fisiologias que tornam os estereótipos rotineiros, como se fossem um destino. E se as estruturas do pensamento não ficarem enrijecidas pela cultura, elas têm mais nuances, não se fecham nas oposições, abrem-se a combinações, transições e variações.

Podemos pensar de outra forma. Os fractais, por exemplo, não são mais estruturas geométricas e racionais, são um modo de conhecimento que engloba a germinação, a multiplicação, a compatibilidade das diferenças e das variantes. $\mathrm{O}$ conceito de variedade substitui o de oposição, na reflexão sobre a diferença. Assim, o semelhante é, ao mesmo tempo, diferente: é o bastardo que faz a variedade. A variação abre-se a múltiplas possibilidades de criação, de transformação e de enriquecimento.

Em nossas sociedades, a diferença entre os sexos acaba por ser entendida como uma variação, os gêneros se movimentam, sentimo-nos femininos ou masculinos, com fundamento em identidades diferentes, que antes, acreditava-se, eram opostas, mas que podem ser construídas de acordo com variações pessoais. A variação joga com o tempo e não se fixa no espaço. Quando se trata de gênero, ela pode se tornar uma construção de si mesmo e da relação forjada pela história de cada um.

\subsection{Qual é a relação entre o sexo e o gênero?}

Existe o sexo oferecido por natureza, uma fisiologia e uma morfologia com diferenças que servem de apoio às estruturas de pensamento que a cultura imobiliza em oposições elementares. O gênero tenta quebrá-las ao dizer: isso é cultural, o sexo é construído. Mas, ao fazer isso, entra em outro modelo de oposição: natureza e determinismo versus pensamento e liberdade. É preciso passar pelas noções de complexidade e variação, pelos jogos de pensamento cujas estruturas não imobilizam, pois são estruturas nuançadas, com gradações, permitindo infinitas combinações.

A mulher não é a sombra do homem. Cada um é um outro modo de ser, é uma variação do ser no mundo e do ser com o outro. Assim, o negro ou o branco da pele são variações do ser humano, não diferenças de humanidade. A espécie é a mesma, as variações de aparência, no seio da espécie, não afetam aquilo que a constitui. Ela é definida por suas capacidades simbólicas e imaginárias, com variações em suas construções, de acordo com os contextos e as épocas.

São as culturas que tendem a atribuir valores às diferenças. E são esses valores que confinam alguns humanos do lado da admiração e outros do lado do desprezo. 


\section{As meninas no olhar dos meninos, as fêmeas no olhar dos machos}

As representações que se exprimem como estereótipos aos quatro ventos fixam uma categoria de seres humanos não somente num imaginário coletivo, mas em funções, status e papéis. "As meninas, as bonecas, as fêmeas", "precisa ver como elas se vestem", "essa daí é quente, ela é gostosa", "todas vadias", "vagabunda, vadia!", "você quer?”, "você gosta disso, hein?”... Todas são expressões conhecidas e que todo mundo escuta, particularmente as mulheres, o que faz delas o retrato de uma fêmea histérica reduzida a seu sexo e provoca, sem cerimônia, desejo e desprezo. São representações que os homens, por sua idade e seu lugar no grupo, vão partilhando cada vez mais; isso favorece um comportamento pulsional ao qual eles acabam se reduzindo. Ou ao menos eles mantêm um sentimento de superioridade, indiferentes a qualquer sentimento de culpa.

O inverso, a representação que as mulheres têm dos homens, é a de caçadores inveterados que "só pensam naquilo", na "paquera". As mais agitadas fazem deles "estupradores" agressivos, no limite da perversão. As outras pelo menos tomam cuidado para não chamar a atenção dos caçadores com suas roupas. Seus tutores zelam por isso, nas famílias em que as mães levam esse papel muito a sério. Sua "boa educação", escola, meio, cultura, ensina-lhes isso. Esse modo de ser no mundo e com os outros faz uma enorme diferença entre homens e mulheres, meninos e meninas, diferença em que a sexualidade comanda.

Nessa cena, estariam, de um lado, os potenciais predadores, legitimados, segundo sua própria versão, pela natureza (sua fisiologia) e pela provocação daquelas que se oferecem como presas, movidas por uma malícia nativa. De outro lado, as presas potenciais, munidas, para sua desgraça, de uma sedução que elas devem aprender a dissimular. Mas se isso é valorizado, se elas têm liberdade de ser assim, são chamadas de histéricas ou putas.

Ora, segundo as culturas, as personalidades, eles e elas podem conciliar-se, apoiados no sentimento de uma sublimação instável do desejo, da ética (moral e conformidade) ou da estética (arte, gosto). Mas ainda assim, neste caso, a mulher é sempre mais protegida do que propriamente promovida.

Deixando à parte o esforço cultural (jurídico, político, científico), os dois sexos ainda estão fadados a uma diferença que não é nem igualdade nem simetria, apesar da complementaridade sexual da espécie: essa 
complementaridade, mesmo emancipada do instinto, contrariamente aos animais, é sujeita a representações, instaura uma relação de subordinação, de exploração, de predação e, no melhor dos casos, de proteção. É isso que testemunham os milênios de história das sociedades humanas.

O século XX e o início do século XXI, nas sociedades democráticas, laicas, ocidentais, estão tentando, com muita dificuldade, combater essas representações. Elas o fazem por meio das leis, apoiadas pelo avanço da ciência, pela consciência dos direitos humanos, que tentam "libertar" as mulheres e admiti-las com igualdade de dignidade e de capacidades humanas com o outro sexo, com os homens.

Nessas sociedades, as raras mulheres chefes, empresárias, cientistas, universitárias, artistas, mulheres livres de disporem de seus corpos e de valorizarem suas capacidades intelectuais, podem cruzar no meio da rua com mulheres cobertas com o véu muçulmano (e que podem até dizer que escolheram se vestir assim) e com prostitutas vindas do leste europeu. Vale lembrar que as mulheres vítimas de violência estão em todas as classes sociais.

A igualdade de direitos dos sexos, nas sociedades humanas, está longe de ser alcançada. Os humanos são vítimas desta tão complexa e extraordinária faculdade de pensar, de representar a realidade, de falar sobre ela, de transformá-la em proveito próprio e, ao mesmo tempo, de sujeitar-se a ela, até mesmo nas representações, a ponto de colaremse estruturalmente ao que a natureza parece sugerir-lhes, nas díades continente/penetrante, recipiente/manejo, passiva/ativo, dominada/ dominante.

No entanto, desprender a consciência da realidade bruta, descolar as representações das fantasias arcaicas, isso é trabalho do pensamento, nas questôes: o que é a ética, o político, a estética e até mesmo o erótico, pensado como ética e estética do gozo.

\subsection{Em nota}

No verão de 2011, o caso Strauss-Kahn ilustrou a armadilha trágica à qual os sexos estão sujeitos. Ninguém pode provar nada a respeito de uma realidade que deveria ser isenta de imaginário, mas na qual as representações ordinárias tiveram um papel enorme. De um lado, um homem poderoso, rico, branco (ainda por cima francês e judeu), com reputação de paquerador e, portanto, de predador e, de outro lado, uma imigrante negra, arrumadeira. Entre os dois, um evento sexual 
que escapou aos olhares. Uma se diz vítima de estupro, o outro admite uma falha moral para com os seus, mas alega uma relação consentida, não paga. Depois, o arquivamento do processo por um tribunal penal americano.

Tomando o partido da mulher (advogados, feministas), seus defensores clamam que esta só pode ter sido violentada, pois sua palavra não pode ser contestada. O estuprador deve ser castigado com degradação, humilhação, prisão, grande compensação financeira à vítima. Tomando o partido do homem, seus apoiadores baseiam-se nos indícios das motivações da mulher: dinheiro em primeiro lugar, seguido de manipulações cercadas de múltiplas mentiras.

As representações clássicas fazem desse caso um pretexto para que as feministas relancem o combate pela defesa das mulheres vítimas dos machos predadores, ocupando a mídia. Os amigos de Strauss-Kahn e os homens em geral não fazem alarde: ocidentais, eles carregam a culpa de terem oprimido as mulheres em todos os lugares e em todos os séculos, envergonhados pela reputação desse sedutor inveterado (Strauss-Kahn). Este vai pagar por todos os homens, e a solidariedade pública a ele pode custar caro. Somente sua mulher pode manifestá-la, podendo ser aprovada ou compreendida.

Ainda que se tratasse de uma tentativa de extorsão de dinheiro, já que ninguém tem a prova dos fatos reais e de seu significado, a história serviu para criminalizar as representações das quais as mulheres são vítimas, há séculos, fazendo do incriminado o símbolo da opressão sofrida, mesmo correndo-se o risco de uma condenação injusta. Reviravolta de representações com odores de vingança cega que dá a esse caso um ar de sintoma, muito mais do que de uma elaboração. O sintoma é um sinal, ele mesmo é um mal, ele não é portador da simbolização que permitiria a evolução de uma problemática complexa.

\section{Referências}

Barus-Michel, J. (2009). Désir, passion, érotisme. L'expérience de la jouissance. Toulouse: Erès.

Beauvoir, S. (1949). Le deuxième sexe. Paris: Gallimard. 
Foucault, M. (1976). Histoire de la sexualité 1. La volonté de savoir. Paris: Gallimard.

Foucault, M. (1984). Histoire de la sexualité 2. L'usage des plaisirs. Paris: Gallimard.

Freud, S. (1932). Nouvelles conférences sur la psychanalyse. La féminité. Paris: Gallimard.

Héritier, F. (2005). Hommes, femmes, la construction de la différence. Paris: Ed. Le Pommier, Cité des Sciences et de l'Industrie.

Lacan, J. (1975). Le séminaire, livre XX (1972-1973) Encore. Paris: Le Seuil.

Lévi-Strauss, C. (1958). L’Anthropologie structurale. t. 1. Paris: Plon. 